\title{
OPEN Assessment of total and regional bone mineral density using bioelectrical impedance vector analysis in elderly population
}

\author{
Hsueh-Kuan Lu ${ }^{1}$, Chung-Liang Lai ${ }^{2}$, Li-Wen Lee ${ }^{3}$, Lee-Ping Chu ${ }^{4}$ \& Kuen-Chang Hsieh ${ }^{5 \bowtie}$
}

This study aimed to investigate the relationship between bone mineral density (BMD) and heightadjusted resistance $(R / H)$, reactance $(X c / H)$ and phase angle $(P h A)$. A total of 61 male and 64 female subjects aged over 60 years were recruited from middle Taiwan. The $R$ and $X c$ were measured using Bodystat Quadscan 4000 at a frequency of $50 \mathrm{kHz}$. BMD at the whole body, L2-L4 spine, and dual femur neck (DFN), denoted as $\mathrm{BMD}_{\text {Total, }} \mathrm{BMD}_{\mathrm{L2}-\mathrm{L} 4 \text {, }}$ and $\mathrm{BMD}_{\mathrm{DFN}}$, were calculated using a Hologic DXA scanner. The R-Xc graph was used to assess vector shift among different levels of BMD. BMD was positively correlated with $\mathrm{Xc} / \mathrm{H}$ and negatively correlated with $\mathrm{R} / \mathrm{H}(p<0.001)$. The General Linear Model (GLM) regression results were as follows: $\mathrm{BMD}_{\text {Total }}=1.473-0.002 \mathrm{R} / \mathrm{H}+0.007 \mathrm{Xc} / \mathrm{H}, r=0.684$; $\mathrm{BMD}_{\mathrm{L} 2-\mathrm{L} 4}=1.526-0.002 \mathrm{R} / \mathrm{H}+0.012 \mathrm{Xc} / \mathrm{H}, r=0.655 ; \mathrm{BMD}_{\mathrm{DFN}}=1.304-0.002 \mathrm{R} / \mathrm{H}+\mathrm{Xc} / \mathrm{H}, r=0.680$; $p<0.0001$. Distribution of vector in the R-Xc graph was significantly different for different levels of $\mathrm{BMD}_{\text {Total, }} B M D_{\mathrm{L} 2-\mathrm{L} 4}$ and $B M D_{\mathrm{DFN}} . \mathrm{R} / \mathrm{H}$ and $\mathrm{XC} / \mathrm{H}$ were correlated with $\mathrm{BMD}$ in the elderly. The linear combination of $\mathrm{R} / \mathrm{H}$ and $\mathrm{Xc} / \mathrm{H}$ can effectively predict the BMD of the whole body, spine and proximal femur, indicating that BIVA may be used in clinical and home-use monitoring tool for screening BMD in the elderly in the future.

The bones act as a supportive structure for the human body. The mineral content of human bone tissue provides bone its architecture and strength ${ }^{1}$. Bone strength is directly related to bone mineral density (BMD) and a decrease in BMD is associated with increased fracture risk ${ }^{2}$. Changes in bone mineral content (BMC) and BMD are age- and gender-dependent. With aging, BMC and BMD increase with increasing age, reaching a maximum at the 20 s, and then slowly decline over time in both genders ${ }^{3}$. In postmenopausal women, a low level of estrogens further accelerates bone loss. For women, the overall lifelong decrease in BMD ranges up to 58\% in the femoral neck and $42 \%$ in the spine whereas the rate of decrease in BMD was two-thirds of that in women for femoral neck and only one-fourth of that in women for the lumbar spine than $\operatorname{men}^{4}$. Therefore, women also have a higher risk of osteoporotic fracture than men. The lifetime risk of fracture is estimated to be $44 \%$ for women aged 60 years old while the risk is $25 \%$ for the men ${ }^{5}$. Osteoporotic fracture is a serious health issue that can lead to dependency, morbidity, and mortality. With the increasing trend in life expectancy, the total number and associated costs of osteoporotic fractures continue to rise globally.

Osteoporosis affects the skeleton disproportionately. Thus, BMD should be measured at specific fracture sites of interest such as the spine, proximal femur, and forearm for accurate risk assessment. Common bone densitometries include dual-energy X-ray absorptiometry (DXA), quantitative CT (QCT), and quantitative ultrasound (QUS) ${ }^{6}$. DXA is considered the gold standard method in clinical practice. A DXA scanner uses two different energies of X-ray to partition the body mass into BMC and soft tissue and calculate the corresponding BMD. However, the DXA scanner has the disadvantages of high cost and limited availability and therefore may not be suitable for large scale study.

Bioelectrical impedance analysis (BIA) can be used to calculate body composition based on the electrical properties of the body, assuming the measured body part is a cylindrical shape with a fixed cross-sectional area, the body composition is homogeneous, the distribution of current density is consistent and the body is under

\footnotetext{
${ }^{1}$ General Education Center, National Taiwan University of Sport, Taichung 404, Taiwan, ROC. ${ }^{2}$ Department of Occupational Therapy, Asia University, Taichung 413, Taiwan, ROC. ${ }^{3}$ Department of Diagnostic Radiology, Chang Gung Memorial Hospital, Chiayi 613, Taiwan, ROC. ${ }^{4}$ Department of Orthopedics, China Medical University Hospital, Taichung 404, Taiwan, ROC. ${ }^{5}$ Big Data Center, National Chung Hsing University, Taichung 402, Taiwan,






\begin{tabular}{|l|l|l|l|}
\hline & Total $(\mathbf{n}=125)$ & Female $(\mathbf{n}=\mathbf{6 4})$ & Male $(\mathbf{n}=\mathbf{6 1})$ \\
\hline Age $($ year $)$ & $65.97 \pm 4.84(60.0,83.4)$ & $66.67 \pm 5.63(60.0,83.4)$ & $65.22 \pm 3.72(60.7,74.5)$ \\
\hline Height $(\mathrm{m})$ & $1.58 \pm 0.10(1.43,1.83)$ & $1.52 \pm 0.05(1.43,1.66)$ & $1.66 \pm 0.09(1.50,1.83)^{* *}$ \\
\hline Weight $(\mathrm{kg})$ & $65.76 \pm 16.25(39.70,105.8)$ & $58.60 \pm 12.66(39.70,93.42)$ & $73.54 \pm 16.21(43.80,105.8)^{* *}$ \\
\hline BMI $\left(\mathrm{kg} / \mathrm{m}^{2}\right)$ & $25.85 \pm 4.73(16.48,41.60)$ & $25.44 \pm 5.49(16.48,41.60)$ & $26.29 \pm 3.75(19.47,34.2)$ \\
\hline $\mathrm{Z}(\mathrm{ohm})$ & $527.1 \pm 95.5(373.9,765.9)$ & $589.33 \pm 65.2(454.2,765.9)$ & $459.6 \pm 75.4(373.9,739.5)^{* *}$ \\
\hline $\mathrm{R}(\mathrm{ohm})$ & $524.2 \pm 95.6(370,762)$ & $586.4 \pm 65.0(452.0,762.0)$ & $456.7 \pm 75.5(370.0,737.0)^{* *}$ \\
\hline $\mathrm{Xc}(\mathrm{ohm})$ & $54.4 \pm 8.1(40,77)$ & $57.85 \pm 7.86(40.0,77.0)$ & $50.67 \pm 6.50(41.0,62.0)^{* *}$ \\
\hline $\mathrm{R} / \mathrm{H}(\mathrm{ohm} / \mathrm{m})$ & $333.6 \pm 73.6(226.8,508.0)$ & $386.47 \pm 42.07(297.4,508.0)$ & $276.22 \pm 55.04(226.8,491.3)^{* *}$ \\
\hline $\mathrm{Xc} / \mathrm{H}(\mathrm{ohm} / \mathrm{m})$ & $34.5 \pm 6.0(23.3,51.3)$ & $38.1 \pm 5.7(26.9,51.3)$ & $30.6 \pm 4.3(23.3,40.7)^{* *}$ \\
\hline $\mathrm{PhA}\left({ }^{\circ}\right)$ & $6.04 \pm 0.91(4.41,8.97)$ & $5.65 \pm 0.62(4.41,7.0)$ & $6.42 \pm 1.01(4.73,9.0)^{* *}$ \\
\hline $\mathrm{BF} \%(\%)$ & $38.2 \pm 10.3(17.1,56.1)$ & $45.2 \pm 7.5(25.5,56.1)$ & $30.7 \pm 7.1(17.1,43.1)^{* *}$ \\
\hline $\mathrm{BMD}_{\text {Total }}\left(\mathrm{g} / \mathrm{cm}^{2}\right)$ & $1.19 \pm 0.14(0.92,1.60)$ & $1.11 \pm 0.09(0.92,1.41)$ & $1.28 \pm 0.14(1.00,1.60)^{* *}$ \\
\hline $\mathrm{BMD}_{\mathrm{L} 2-\mathrm{L} 4}\left(\mathrm{~g} / \mathrm{cm}^{2}\right)$ & $1.26 \pm 0.19(0.93,1.72)$ & $1.18 \pm 0.14(0.93,1.65)$ & $1.35 \pm 0.20(0.97,1.72)^{* *}$ \\
\hline $\mathrm{BMD}_{\mathrm{DFN}}\left(\mathrm{g} / \mathrm{cm}^{2}\right)$ & $0.99 \pm 0.18(0.66,1.480)$ & $0.89 \pm 0.11(0.66,1.28)$ & $1.10 \pm 0.17(0.76,1.48)^{* *}$ \\
\hline
\end{tabular}

Table 1. Subject demographic. $P h A$ phase angle, $B F \%$ percentage body fat. ${ }^{*} \mathrm{p}<0.05 .{ }^{* *} \mathrm{p}<0.001$. ${ }^{\mathrm{a}} \mathrm{Data}$ are expressed as mean \pm standard deviation ( $\min , \max$ ). ${ }^{\mathrm{b}} \mathrm{Z}$, impedance, $\mathrm{R}$, resistance, $\mathrm{Xc}$, reactance, $\mathrm{R} / \mathrm{H}$, resistance standardized for height, $\mathrm{Xc} / \mathrm{H}$, reactance standardized for height. 'Subscript total, L2-L4, and DFN denote whole body, AP spine L2-L4, and dual femur neck, respectively.

stable hydration status without water-electrolyte imbalance. Violation of the prior assumptions may cause errors in measurement. Currently, BIA is a well-known method for calculating body composition in clinical practice and field studies owing to its portability, low cost, and high precision. The mineral content is a less established BIA estimate which can be obtained from modern BIA. The performance for predicting BMC using mineral estimates by BIA was reported to be high in correlation but with the limited agreement in healthy young adults ${ }^{7}$.

The phase shift is defined as the phase angle (PhA), which is a BIA parameter directly calculated from the BIA electrical components of resistance $(\mathrm{R})$ and reactance $(\mathrm{Xc})$. Since the human cell membrane is a phospholipid bilayer, forming a double-layered sheet with the hydrophilic end outside and hydrophobic layer inside, it can behave as a capacitor. In a resistor/capacitor circuit connected to an AC voltage, there is a phase difference between current and voltage sinusoidal waveform. Resistance quantifies the opposition to the flow of a current through biological fluids and tissue. All in all, the reactance (Xc) depends on the integrity and quantity of the cell membrane, while the resistance $(\mathrm{R})$ is related to the total body fluid and ion composition. Therefore, vector components represent cellular mass and function in bioelectrical impedance vector analysis (BIVA). At a frequency of $5-50 \mathrm{kHz}$, the current passes through an extracellular fluid but not intracellular fluid. Therefore, most BIA devices measure $\mathrm{PhA}$ at a frequency of $50 \mathrm{kHz}$. PhA results depend on several biological factors such as cell mass, integrity, and permeability of cell membrane, and the amount of fluid in the intracellular and extracellular spaces. Unlike the body composition estimates by BIA which are calculated via the application of empirical equations, $\mathrm{PhA}$ is an assumption-free raw BIA parameter and therefore $\mathrm{PhA}$ is less biased and can be applied in patients with different hydration status. The applications of $\mathrm{PhA}$ attract researchers attention and have been applied to study muscle quality and muscle strength ${ }^{8-11}$, sarcopenia $^{12}$, physical performance ${ }^{13}$, inflammatory markers ${ }^{14}$, nutrition status ${ }^{15}$, disease prognosis ${ }^{16}$ and risk of mortality ${ }^{17}$. A recent study by Antunes et al. ${ }^{18}$ reported that $\mathrm{PhA}$ is correlated to BMD in the elderly population, launching a new application of PhA in studying BMD.

The bioelectrical impedance vector analysis (BIVA) method was proposed in 1994 by Piccoli et al. ${ }^{19}$ by plotting 2-dimensional vectors on height-standardized R and Xc axes, which is called the R-Xc graph. Alternatively, any point in the 2-dimensional space of the R-Xc graph can be described by the position vector with length and angle components. Vector shift due to low or high Xc indicates a decrease or increase of dielectric mass (cell membranes and tissue interfaces $)^{20}$. Change in vector length can be used to represent hydration status, with lengthening of the vector indicates fluid loss and shortening of the vector indicates fluid gain. The concept is an important precursor for BIVA to provide information on body cell mass, cell integrity, and hydration status using vector length and distribution. Currently, BIVA has been used to assess the hydration and nutritional status in hemodialysis patients ${ }^{21,22}$, liver cirrhosis patients ${ }^{23}$, critically ill patients ${ }^{24}$, obese adults ${ }^{25}$, and nutritional status of healthy adults ${ }^{26}$.

PhA has been increasingly used in nutritional and clinical disease assessment and BIVA has been used to evaluate water content, nutritional status, and skeletal muscle function. However, there are only few studies regarding the application of $\mathrm{PhA}$ in estimating $\mathrm{BMD}^{18}$. This study was aimed to investigate the relationship between BIVA parameters and BMD in total body and body segments in the elderly population. The vector shift in the R-Xc graph was also examined.

\section{Results}

Table 1 shows descriptive statistics of anthropometric and bioelectrical and body composition variables by gender. There was no significant difference in the age and BMI between men and women. However, the percentage body fat of male subjects was significantly lower than that of female subjects, and the BMD of male subjects in 


\begin{tabular}{|c|c|c|c|c|c|}
\hline & \multirow[b]{2}{*}{ Constants } & \multicolumn{2}{|c|}{ Coefficients } & \multirow[b]{2}{*}{$\mathbf{r}$} & \multirow[b]{2}{*}{ p (model) } \\
\hline & & $\mathbf{R} / \mathbf{H}$ & $\mathrm{Xc} / \mathrm{H}$ & & \\
\hline $\mathrm{BMD}_{\text {Total }}$ & 1.4732 & $-0.0016^{\star *}$ & $0.0066^{*}$ & 0.684 & $<0.0001$ \\
\hline $\mathrm{BMD}_{\mathrm{L} 2-\mathrm{L} 4}$ & 1.5259 & $-0.0021^{* *}$ & $0.0121^{*}$ & 0.655 & $<0.0001$ \\
\hline $\mathrm{BMD}_{\mathrm{DEN}}$ & 1.3044 & $-0.0019^{* *}$ & $0.0093^{*}$ & 0.680 & $<0.0001$ \\
\hline
\end{tabular}

Table 2. Results from the GLM regression analysis showing similar associations between resistance and reactance standardized for height and bone mineral density. All distributions of residuals were compatible with a normal distribution. ${ }^{*} \mathrm{p}<0.05 .{ }^{* *} \mathrm{p}<0.001$.

all different regions tested was significantly higher than that of female subjects $(p<0.001)$. In addition, the values of $\mathrm{Z}, \mathrm{R}, \mathrm{Xc}, \mathrm{R} / \mathrm{H}, \mathrm{Xc} / \mathrm{H}$ and $\mathrm{PhA}$ were all significantly different between genders $(p<0.001)$.

Multiple regression analysis was used to predict $\mathrm{BMD}_{\text {total }}, \mathrm{BMD}_{\mathrm{L} 2-\mathrm{L} 4}$, and $\mathrm{BMD}_{\mathrm{DFN}}$ by $\mathrm{R} / \mathrm{H}$ and $\mathrm{Xc} / \mathrm{H}$. Table 2 shows the results of the GLM analysis, including regression weights (coefficients) and the correlation between predicted and actual BMD values. All three regions of BMD estimates were positively correlated with $\mathrm{Xc} / \mathrm{H}$ and negatively correlated with $\mathrm{R} / \mathrm{H}$. The overall models were significant $\mathrm{r}(p<0.001)$ with moderate correlation $(r=0.655-0.684)$, indicating a linear combination of $\mathrm{R} / \mathrm{H}$ and $\mathrm{Xc} / \mathrm{H}$ predicted $\mathrm{BMD}$ in the whole body, spine, and proximal femur.

Subjects were then divided into three subgroups regardless of gender, according to BMD levels: the lowest (group I), middle (group II) and highest (group III) tertiles of BMD. The R-Xc graph and 95\% confidence ellipses of the $\mathrm{BMD}_{\text {total }}, \mathrm{BMD}_{\mathrm{L} 2-\mathrm{L} 4}$, and $\mathrm{BMD}_{\mathrm{DFN}}$ for the three subgroups were shown in Fig. 1a-c, respectively. The results of Hotelling's $\mathrm{T}^{2}$ test showed a significant vector displacement between the BIVA measured in the three subgroups in the whole body, spine, and proximal femur $(p<0.05)$.

Scatter plots with linear regression lines of BMD versus $\mathrm{PhA}$ in the whole body, spine, and proximal femur were shown in Fig. $2 \mathrm{a}-\mathrm{c}$, respectively. In the three anatomical locations, there were moderately positive correlations between BMD and PhA $(r=0.538-0.590)$.

\section{Discussion}

This study showed that BIVA outcomes including $\mathrm{PhA}$, height-adjusted $\mathrm{R}(\mathrm{R} / \mathrm{H})$, and $\mathrm{Xc}(\mathrm{Xc} / \mathrm{H})$, were related to BMD levels in the whole body, spine, and proximal femur in the elderly population. This provided a new biomarker for BMD using BIVA. To our knowledge, only one study has related PhA as a BMD determinant and no study has related vector shift in the RXc graph with the changes in BMD. In the study by Antunes et al. ${ }^{18}$, a significant correlation $(\mathrm{p}<0.001)$ was found between $\mathrm{PhA}$ and BMD in the total body, femur, femoral neck, and forearm with correlation coefficients of $0.475,0.524,0.450$, and 0.437 , respectively, but no correlation was found in the spine. The cause of the discrepancy remains unclear. This study is consistent with Antunes et al. showing a moderately positive correlation between BMD and PhA.

The phase angle is the most established BIVA parameter. It is considered to be age- and gender-dependent ${ }^{27}$. When adding body composition parameters as variables, age explained most of the variability in $\mathrm{PhA}$, followed by the fat-free mass (FFM) in healthy subjects ${ }^{28}$. In a population study, PhA was found to be associated with frailty and mortality, independent of age and comorbidity ${ }^{17,29}$. Additionally, FFM is positively correlated with $\mathrm{BMD}$ with varying strength of the correlation, depending on the sites of $\mathrm{BMD}^{30,31}$. Therefore, it is reasonable to expect that PhA may be correlated with BMD. However, more research is needed to explore whether potential confounding variables such as age, gender, height, and weight can affect the correlational relationship between $\mathrm{PhA}$ and $\mathrm{BMD}$ in different body regions.

$\mathrm{R}$ and $\mathrm{Xc}$ are BIVA parameters directly measured from the BIA device. By normalized to body height, $\mathrm{R} / \mathrm{H}$ and $\mathrm{Xc} / \mathrm{H}$ can provide a qualitative measure of soft tissue that does not depend on body size ${ }^{20}$. This study showed that $\mathrm{BMD}$ was positively correlated with $\mathrm{Xc} / \mathrm{H}$ but negatively correlated with $\mathrm{R} / \mathrm{H}$. Each unit increased in $\mathrm{Xc} / \mathrm{H}$ $(\mathrm{Ohm} / \mathrm{m})$ was associated with $0.0066 \mathrm{~g} / \mathrm{cm}^{2}$ increase in $\mathrm{BMD}_{\text {total }}$ whereas each unit increased in $\mathrm{R} / \mathrm{H}(\mathrm{Ohm} / \mathrm{m})$ was associated with a $0.0016 \mathrm{~g} / \mathrm{cm}^{2}$ decrease in $\mathrm{BMD}_{\text {total }}$. A similar trend was observed for estimating $\mathrm{BMD}$ in the spine and proximal femur in this study. This is the first study suggesting that BIVA variables might be predictors for BMD in the elderly population. Interestingly, this trend has also been observed in previous studies where muscle strength was positively correlated with $\mathrm{Xc} / \mathrm{H}$ and negatively correlated with $\mathrm{R} / \mathrm{H}^{8,10}$. Muscle strength is a positive predictor for $\mathrm{BMD}^{32,33}$, and this might explain why $\mathrm{R} / \mathrm{H}$ and $\mathrm{Xc} / \mathrm{H}$ predict both muscle strength and $\mathrm{BMD}$ in a similar direction.

In the BIVA plot, a vector has angle as well as magnitude information in the $\mathrm{R} / \mathrm{H}$ and $\mathrm{Xc} / \mathrm{H}$ directions. In contrast, a PhA only has the directional component without providing information on its distance. Indeed, vectors of varying length share the same $\mathrm{PhA}$ in the RXc graph. Therefore, the vector analysis approach has the potential of presenting more diverse information on biological activity compared to $\mathrm{PhA}$ alone. In addition, the BIA device is a reliable tool, providing measurement with a precision error of $2-3 \%{ }^{34,35}$. Currently, BIVA has been used to differentiate obesity (higher PhA and short length), athletes (higher PhA, long length), cachexia (lower $\mathrm{PhA}$, long length), and weakens (normal PhA and short length). In this study, higher BMD was associated with a vector of higher $\mathrm{PhA}$ and shorter length. This may provide a diagnostic tool for estimating BMD in the elderly population at risk of osteoporosis.

The present study showed that $\mathrm{PhA}, \mathrm{R} / \mathrm{H}$, and $\mathrm{Xc} / \mathrm{H}$ estimates were correlated with $\mathrm{BMD}$. A low $\mathrm{PhA}$ is associated with osteoporosis, despite age and gender control ${ }^{18,36}$. BIA device is well-known for personal body fat 

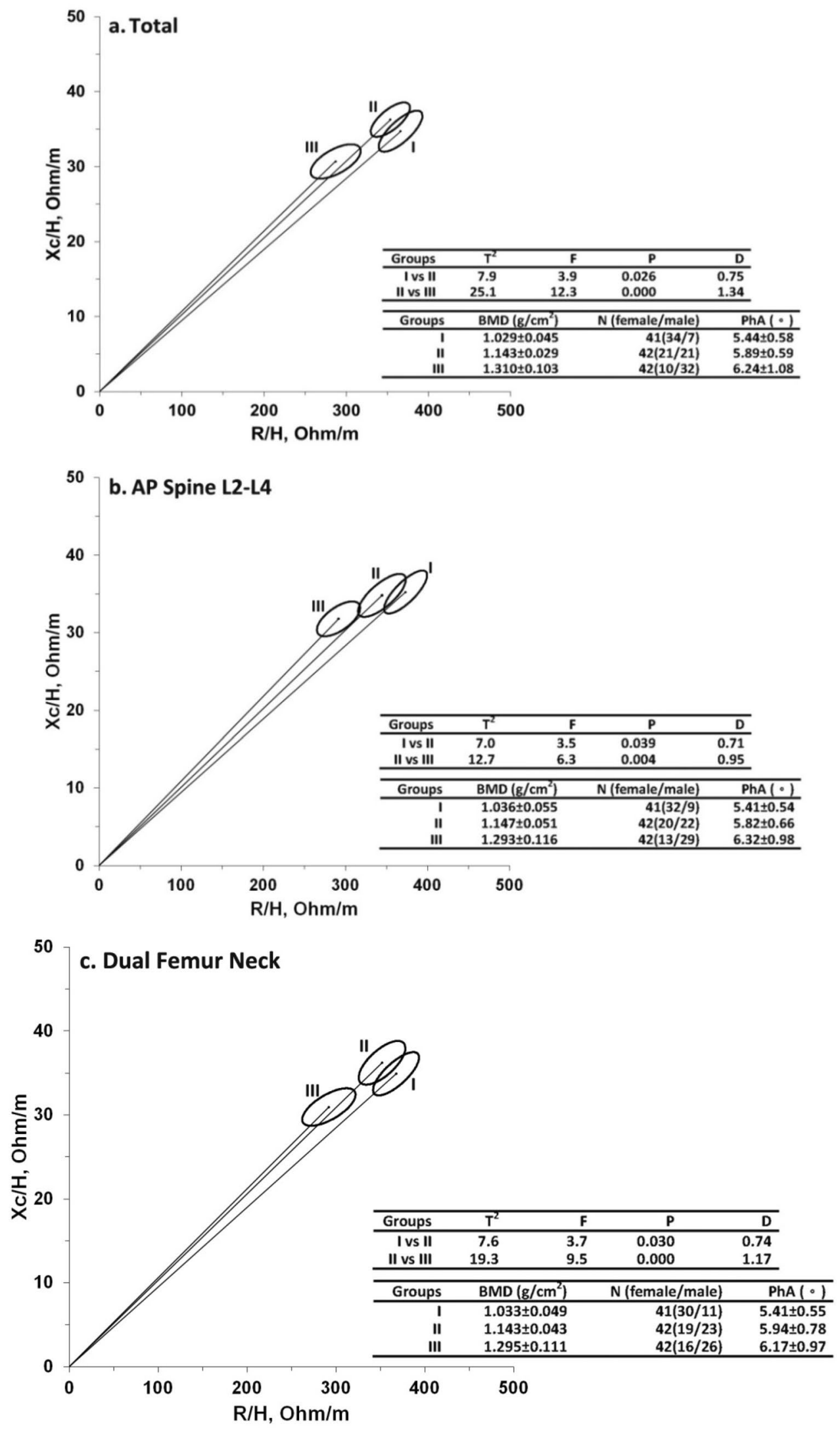

Figure 1. Mean graph with 95\% confidence interval ellipse. (a). BMD-Total; (b) BMD-AP Spine L2-L4; (c) BMD-Dual Femur Neck; Hotelling's $\mathrm{T}^{2}$ test value with the corresponding $\mathrm{F}$ test and $\mathrm{P}$ values, and the Mahalanobis' generalized distance D. PhA phase angle, Group I participants with the lowest BMD level, Group II participants with middle BMD level, Group III patients with the highest BMD level. 


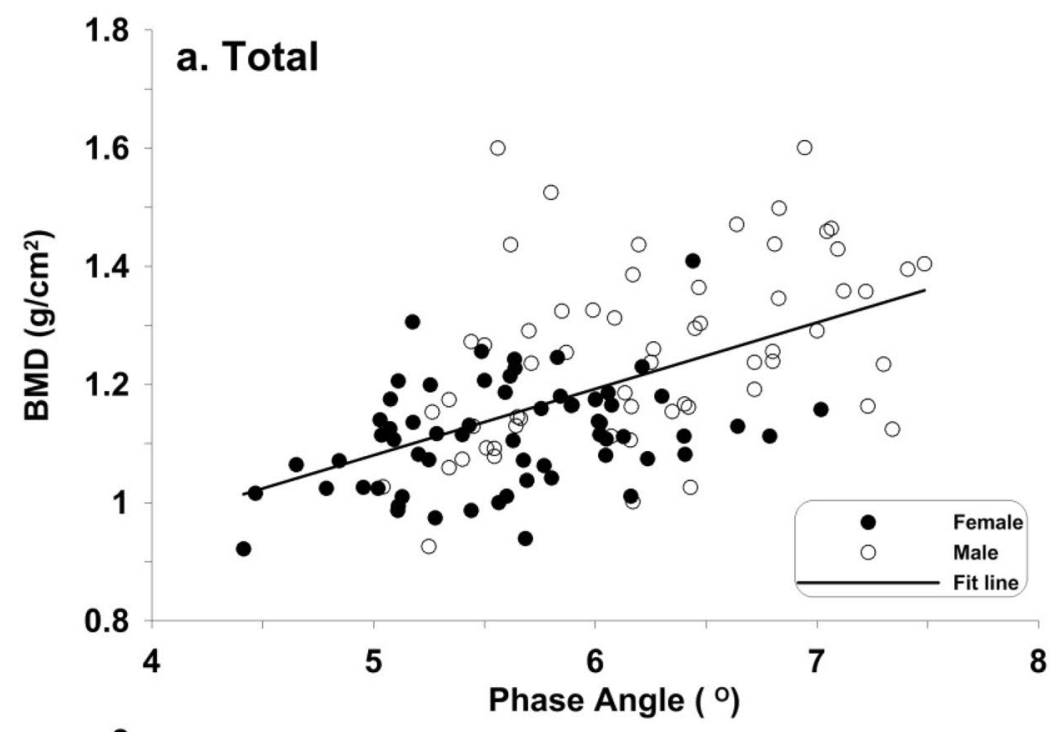

\section{2 b. AP Spine L2-L4}
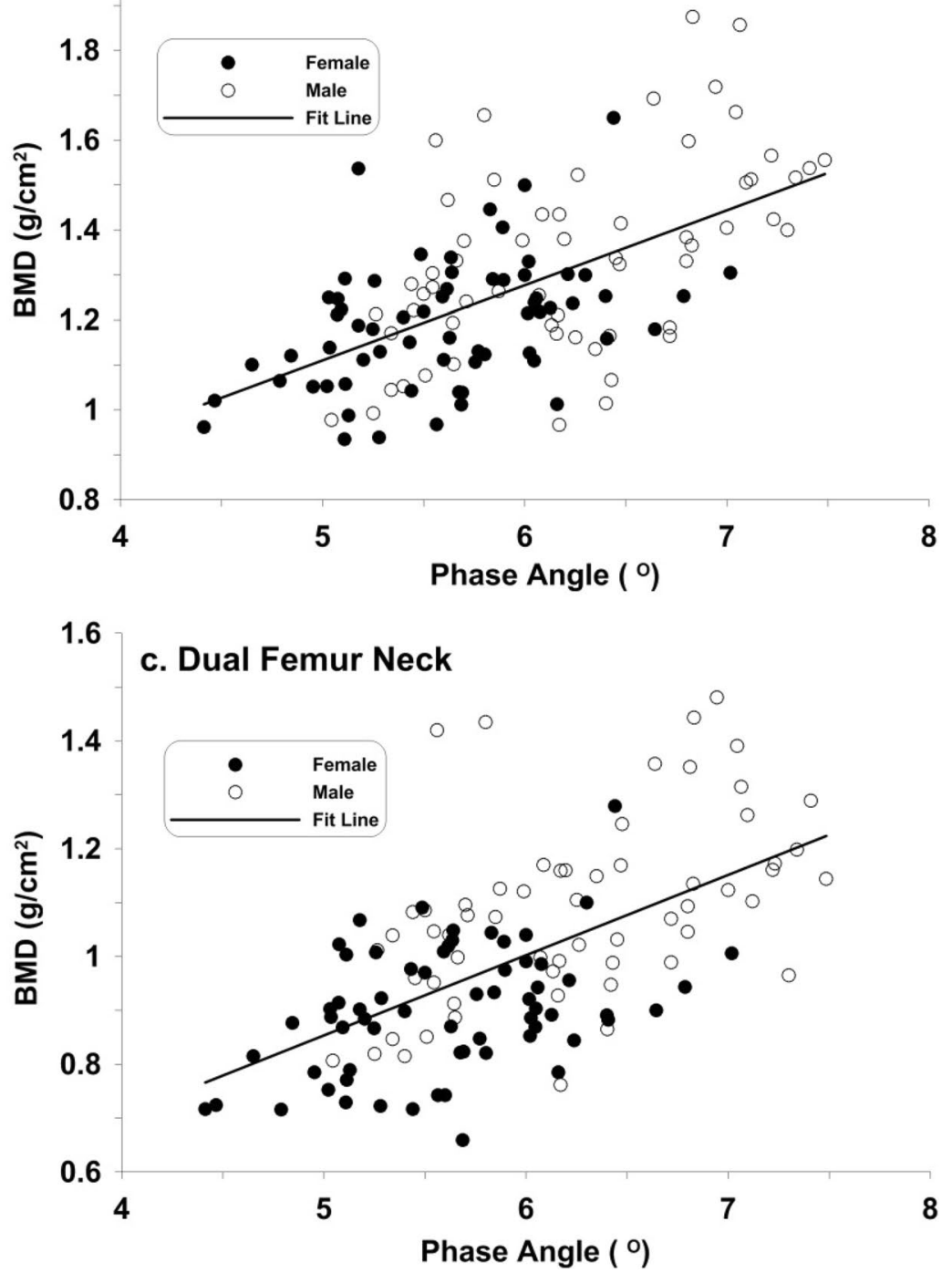

Figure 2. Scatter diagram of phase angle and bone density. (a) Total $\left(\mathrm{BMD}_{\text {total }}=0.519+0.112 \mathrm{PhA}, \mathrm{r}=0.538\right)$; (b) AP Spine L2-L4 $\left(\mathrm{BMD}_{\mathrm{L} 2-\mathrm{L} 4}=0.277+0.155 \mathrm{PhA}, \mathrm{r}=0.582\right)$; (c) Dual Femur Neck $\left(\mathrm{BMD}_{\mathrm{FDN}}=0.108+0.148\right.$ $\mathrm{PhA}, \mathrm{r}=0.590)$. 
monitoring at home. However, the current home-use models do not provide BIVA estimates. With the development of home-use BIA devices providing BIVA estimates, a self-screening tool for osteoporosis may be created, aiding in the early diagnosis and treatment of osteoporosis.

Studies have shown that skeletal muscle mass ${ }^{37,38}$ and strength ${ }^{39,40}$ are correlated with BMD. Since BIA parameters can be used as an alternative to muscle mass and muscle strength ${ }^{8,10}$, it is reasonable that there is a correlation between skeletal muscle mass and strength with BMD. Although BIA estimates skeletal muscle mass and strength indirectly using electrical parameters, it is a still a valuable tool due to its high precision and low cost and could facilitate the evaluation of BMD in field studies.

This study has several limitations. First, a cause-effect relationship between BMD and height-adjusted R and Xc could not be established. Second, subgroup analysis was not performed due to the small sample size. Third, osteoporosis is a complex disease governed by a wide range of phenotypes regulated by genetic and environmental factors ${ }^{41}$. However, these factors such as age, gender, ethnicity, family history, physical activity were not included as variables in the regression analysis. Further study is still needed to investigate the impact of these factors on BMD.

\section{Methods}

Participants. This is a cross-sectional study conducted between January 2016 and December 2016 at the Department of Rehabilitation of the Taichung Hospital in Taiwan. Male and female subjects aged above 60 years were recruited via outpatient clinics at the Department of Rehabilitation of the Taichung Hospital. Written informed consent was obtained from all participants after explaining the study. Subjects interested in participating underwent a screening process by trained health professionals to determine if they qualify for the study. Exclusion criteria were subjects with electrolyte imbalance, cancer, inflammation (serum TNFa $\geq 0.753-$ $1.660 \mathrm{pg} / \mathrm{mL}$ or IL- $6 \geq 7 \mathrm{pg} / \mathrm{mL}$ ), severe cardiovascular disease, and lung disease. A total of 61 males (aged $65.2 \pm 3.7$ years) and 64 females $(66.7 \pm 5.6)$ who met the criteria were scheduled for the measurements. Before the test, participants were asked to start their 8-h fast after breakfast, abstain from alcohol and avoid vigorous exercise for $48 \mathrm{~h}$, and diuretics for 7 days. Before taking the measurements, participants were asked to remove all cognitive content from their body and empty their bladder. All measurements were performed with participants wearing light clothes and no shoes at room temperature $\left(26-28^{\circ} \mathrm{C}\right)$. The total study time was $1-1.5 \mathrm{~h}$ on the same afternoon section.

Ethics statement. The study protocol was approved by the Institutional Review Board of the Tsaotun Psychiatric Center (IRB_1050125) and was registered on the Chinese Clinical Trial Registry (ChiCTROOC-16008825). The investigation was conducted in accordance with the 2008 version of the Declaration of Helsinki.

Body index measurements. Weight was recorded using an electrical scale (Tanita BC418MA, Japan) adjusted to the nearest $0.1 \mathrm{~kg}$ and height was measured using a stadiometer (Holtain Ltd, Crosswell, Wales, UK) adjusted to the nearest $0.5 \mathrm{~cm}$. Body mass index (BMI) was calculated by divided weight in kilograms by height in meter squared.

Bioelectrical impedance analysis measurements. The QuadScan 4000 (Bodystate Ltd, British Islands) was used to record BIA parameters with QuadScan medical graded electrodes. The instrument was calibrated at the beginning of each day of use with a calibrator supplied with the device. A frequency of $50 \mathrm{kHz}$ was used in the hand-to-foot model with participants in a supine position after lying down for at least $10 \mathrm{~min}$. A pair of measuring and current electrodes were placed on the dorsal side of the right hand and another pair on the dorsal surface of the right foot with a $5 \mathrm{~cm}$ distance apart at the same anatomical site. Parameters including resistance $(\mathrm{R})$ and reactance $(\mathrm{Xc})$ were measured. Impedance $(\mathrm{Z})$ was calculated as $Z=\sqrt{R^{2}+X c^{2}}$. Phase angle $(\mathrm{PhA})$ was calculated as $\mathrm{PhA}=\arctan (X c / R) \times 180^{\circ} / \pi$. For BIVA, $\mathrm{R}$ and $\mathrm{Xc}$ were normalized to height $(\mathrm{H})$ and the R-Xc graph was generated by plotting $\mathrm{Xc} / \mathrm{H}$ versus $\mathrm{R} / \mathrm{H}$.

Dual-energy X-ray absorptiometry measures. Bone estimates were measured using a fan-beam Discovery W scanner (Hologic Inc. Bedford, MA, USA) equipped with software version 5.67. The scanner generates two different energies of X-ray, 100 and $140 \mathrm{kVp}$, to calculate the BMC and soft tissue composition in the scanned region. Before each day of use, a daily machine calibration test according to the manufacturer's instructions was performed using the Hologic spine and whole-body phantoms. For the DXA experiment, participants were positioned in the scanning table, according to manufacturer guidelines, by experienced radiological technicians. $\mathrm{BMD}$ at the whole body, lumbar spine, and proximal femur were denoted as $\mathrm{BMD}_{\text {total }}, \mathrm{BMD}_{\mathrm{L} 2-\mathrm{L} 4}$ and $\mathrm{BMD}_{\mathrm{DFN}}$.

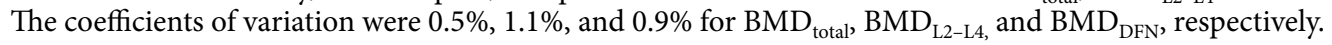

Statistical analysis. Data were presented as mean, standard deviation, minimum, and maximum. Statistical analysis was performed using SPSS version 21 (SPSS Inc., Chicago, IL, USA). Shapiro-Wilk test was used to test if a variable was normally distributed. Student $t$-test was used to determine statistical difference between gender in the variables. ANOVA was used to compare the means between two or more groups of variables. Pearson correlation coefficient was applied to investigate the relationship between two continuous variables. A General Linear Model (GLM) was applied to fit regression models of BMD in different regions using BIVA parameters $(\mathrm{R} / \mathrm{H}$ and $\mathrm{Xc} / \mathrm{H})$. 
A value of $\mathrm{p}<0.05$ was considered statistical significance. BIVA Software $2002^{42}$ was used to plot the R-Xc graph and confidence ellipses for mean vectors. The $95 \%$ confidence ellipses did not overlap was considered statistical significance. The Mahalanobis's generalized distance (D) was used to rank the difference among mean vectors. Hotelling's $\mathrm{T}^{2}$ test was a multivariate extension of the Student's t-test in comparison of mean vectors.

Received: 25 May 2021; Accepted: 12 October 2021

Published online: 27 October 2021

\section{References}

1. Weiner, S. \& Wagner, H. D. The material bone: Structure-mechanical function relations. Annu. Rev. Mater. Sci. 28(1), 271 (1998).

2. Faibish, D., Ott, S. M. \& Boskey, A. L. Mineral changes in osteoporosis: A review. Clin. Orthop. Relat. Res. 443, 28 (2006).

3. Lu, J., Shin, Y., Yen, M.-S. \& Sun, S. S. Peak bone mass and patterns of change in total bone mineral density and bone mineral contents from childhood into young adulthood. J. Clin. Densitom. 19(2), 180 (2016).

4. Riggs, B. et al. Changes in bone mineral density of the proximal femur and spine with aging: Differences between the postmenopausal and senile osteoporosis syndromes. J. Clin. Investig. 70(4), 716 (1982).

5. Nguyen, N. D., Ahlborg, H. G., Center, J. R., Eisman, J. A. \& Nguyen, T. V. Residual lifetime risk of fractures in women and men. J. Bone Miner. Res. 22(6), 781 (2007).

6. Fogelman, I. \& Blake, G. M. Different approaches to bone densitometry. J. Nucl. Med. 41(12), 2015 (2000).

7. Liao, Y.-S. et al. Comparison of bioelectrical impedance analysis and dual energy X-ray absorptiometry for total and segmental bone mineral content with a three-compartment model. Int. J. Environ. Res. Public Health. 17(7), 2595 (2020).

8. Norman, K., Wirth, R., Neubauer, M., Eckardt, R. \& Stobäus, N. The bioimpedance phase angle predicts low muscle strength, impaired quality of life, and increased mortality in old patients with cancer. J. Am. Med. Dir. Assoc. 16(2), 173.e117 (2015).

9. Nunes, J. P. et al. Improvements in phase angle are related with muscle quality index after resistance training in older women. J. Aging Phys. Act. 27(4), 515 (2019).

10. Lee, L. W. et al. Prediction and discrimination of skeletal muscle function by bioelectrical impedance vector analysis using a standing impedance analyzer in healthy Taiwanese adults. PLoS ONE 15(6), e0231604 (2020).

11. Rodríguez-Rodríguez, F., Cristi-Montero, C., González-Ruíz, K., Correa-Bautista, J. E. \& Ramírez-Vélez, R. Bioelectrical impedance vector analysis and muscular fitness in healthy men. Nutrients 8(7), 407 (2016).

12. Basile, C. et al. Phase angle as bioelectrical marker to identify elderly patients at risk of sarcopenia. Exp. Gerontol. 58, 43 (2014).

13. Cooper, C., Campion, G. \& Melton, L. J. 3rd. Hip fractures in the elderly: A world-wide projection. Osteoporos. Int. 2(6), 285 (1992).

14. Tomeleri, C. M. et al. Phase angle is related with inflammatory and oxidative stress biomarkers in older women. Exp. Gerontol. 102, 12 (2018).

15. Oliveira, C. M. et al. The phase angle and mass body cell as markers of nutritional status in hemodialysis patients. J. Ren. Nutr. 20(5), 314 (2010).

16. Gupta, D. et al. Bioelectrical impedance phase angle as a prognostic indicator in breast cancer. BMC Cancer 8, 249 (2008).

17. Norman, K. et al. Cutoff percentiles of bioelectrical phase angle predict functionality, quality of life, and mortality in patients with cancer. Am. J. Clin. Nutr. 92(3), 612 (2010).

18. Antunes, M. et al. Total and regional bone mineral density are associated with cellular health in older men and women. Arch. Gerontol. Geriatr. 90, 104156 (2020).

19. Piccoli, A., Rossi, B., Pillon, L. \& Bucciante, G. A new method for monitoring body fluid variation by bioimpedance analysis: The RXc graph. Kidney Int. 46(2), 534 (1994).

20. Norman, K., Stobäus, N., Pirlich, M. \& Bosy-Westphal, A. Bioelectrical phase angle and impedance vector analysis-clinical relevance and applicability of impedance parameters. Clin. Nutr. 31(6), 854 (2012).

21. Piccoli, A. \& Codognotto, M. Bioimpedance vector migration up to three days after the hemodialysis session. Kidney Int. 66(5), 2091 (2004) (author reply 2092).

22. Jha, V. et al. Body composition analysis with bioelectric impedance in adult Indians with ESRD: Comparison with healthy population. Kidney Int. 69(9), 1649 (2006).

23. Guglielmi, F. W. et al. The RXc graph in evaluating and monitoring fluid balance in patients with liver cirrhosis. Ann. N. Y. Acad. Sci. 873, 105 (1999).

24. Piccoli, A., Pittoni, G., Facco, E., Favaro, E. \& Pillon, L. Relationship between central venous pressure and bioimpedance vector analysis in critically ill patients. Crit. Care Med. 28(1), 132 (2000).

25. Piccoli, A. et al. Discriminating between body fat and fluid changes in the obese adult using bioimpedance vector analysis. Int. J. Obes. 22(2), 97 (1998).

26. Buffa, R., Floris, G. \& Marini, E. Migration of the bioelectrical impedance vector in healthy elderly subjects. Nutrition 19(11-12), 917 (2003).

27. Barbosa-Silva, M. C., Barros, A. J., Wang, J., Heymsfield, S. B. \& Pierson, R. N. Jr. Bioelectrical impedance analysis: population reference values for phase angle by age and sex. Am. J. Clin. Nutr. 82(1), 49 (2005).

28. Gonzalez, M. C., Barbosa-Silva, T. G., Bielemann, R. M., Gallagher, D. \& Heymsfield, S. B. Phase angle and its determinants in healthy subjects: Influence of body composition. Am. J. Clin. Nutr. 103(3), 712 (2016).

29. Wilhelm-Leen, E. R., Hall, Y. N., Horwitz, R. I. \& Chertow, G. M. Phase angle, frailty and mortality in older adults. J. Gen. Intern. Med. 29(1), 147 (2014).

30. Douchi, T. et al. Relative contribution of lean and fat mass component to bone mineral density in males. J. Bone Metab. 21(1), 17 (2003).

31. Ho-Pham, L. T., Nguyen, U. D. \& Nguyen, T. V. Association between lean mass, fat mass, and bone mineral density: A meta-analysis. J. Clin. Endocrinol. Metab. 99(1), 30 (2014).

32. Snow-Harter, C., Whalen, R., Myburgh, K., Arnaud, S. \& Marcus, R. Bone mineral density, muscle strength, and recreational exercise in men. J. Bone Miner. Res. 7(11), 1291 (1992).

33. Henderson, N. K., Price, R. I., Cole, J. H., Gutteridge, D. H. \& Bhagat, C. I. Bone density in young women is associated with body weight and muscle strength but not dietary intakes. J. Bone Miner. Res. 10(3), 384 (1995).

34. Dittmar, M. Reliability and variability of bioimpedance measures in normal adults: Effects of age, gender, and body mass. Am. J. Phys. Anthropol. 122(4), 361 (2003).

35. Piccoli, A. et al. Equivalence of information from single versus multiple frequency bioimpedance vector analysis in hemodialysis. Kidney Int. 67(1), 301 (2005).

36. Tanaka, S. et al. A low phase angle measured with bioelectrical impedance analysis is associated with osteoporosis and is a risk factor for osteoporosis in community-dwelling people: The Yakumo study. Arch. Osteoporos. 13(1), 39 (2018).

37. Lima, R. M. et al. Fat-free mass, strength, and sarcopenia are related to bone mineral density in older women. J. Clin. Densitom. 12, 35 (2009).

38. Stewart, K. J. et al. Fitness, fatness and activity as predictors of bone mineral density in older persons. J. Intern. Med. 252, 381 (2002). 
39. Pettersson, U., Nordstrom, P. \& Lorentzon, R. A comparison of bone mineral density and muscle strength in young male adults with different exercise level. Caleif. Tissue. Int. 64, 490 (1999).

40. Daly, R. M. et al. Gender specific age-related changes in bone density, muscle strength and functional performance in the elderly: A-10 year prospective population-based study. BMC Geriatr. 13, 71 (2013).

41. Ralston, S. H. \& Uitterlinden, A. G. Genetics of osteoporosis. Endocr. Rev. 31(5), 629 (2010).

42. Piccoli, A. \& Pastori, G. BIVA Software 2002 (Department of Medical and Surgical Sciences University of Padova, 2002).

\section{Author contributions}

Conceptualization: H.-K.L., K.-C.H.; data curation: H.-K.L., C.-L.L., K.-C.H.; formal analysis: L.-W.L., K.-C.H.; methodology: H.-K.L., L.-P.C.; supervision: K.-C.H.; visualization: L.-P.C.; writing-original draft: H.-K.L., L.W.L.; writing—review and editing: all authors.

\section{Funding}

This research was supported by a Grant from Research and Development Award Program of the Ministry of Health and Welfare with the award number of PG10601-0241.

\section{Competing interests}

The authors declare no competing interests.

\section{Additional information}

Correspondence and requests for materials should be addressed to K.-C.H.

Reprints and permissions information is available at www.nature.com/reprints.

Publisher's note Springer Nature remains neutral with regard to jurisdictional claims in published maps and institutional affiliations.

(c) (i) Open Access This article is licensed under a Creative Commons Attribution 4.0 International

License, which permits use, sharing, adaptation, distribution and reproduction in any medium or format, as long as you give appropriate credit to the original author(s) and the source, provide a link to the Creative Commons licence, and indicate if changes were made. The images or other third party material in this article are included in the article's Creative Commons licence, unless indicated otherwise in a credit line to the material. If material is not included in the article's Creative Commons licence and your intended use is not permitted by statutory regulation or exceeds the permitted use, you will need to obtain permission directly from the copyright holder. To view a copy of this licence, visit http://creativecommons.org/licenses/by/4.0/.

(C) The Author(s) 2021 